\title{
EDUCACIÓN SUPERIOR FEMENINA Y NUEVAS CONFORMACIONES IDENTITARIAS: JUVENTUD UNIVERSITARIA FEMENINA (1919-1930)
}

\author{
WOMEN'S HIGHER EDUCATION AND NEW \\ IDENTITARIAN CONFORMATION: JUVENTUD \\ UNIVERSITARIA FEMENINA (1919-1930)
}

\author{
Luz Sanfeliu Gimeno \\ Universidad de Valencia (España) \\ orcid.org/0000-0001-9311-4629
}

Recibido el 26-9-2016 y aceptado el 25-1-2017

\begin{abstract}
Resumen: Este artículo analiza la forma en la que a los pocos años de la incorporación de las mujeres a los estudios superiores en España, se constituyó, en 1920, la Juventud Universitaria Femenina (JUF), cuyos objetivos se centraron en construir y atribuir significados a la nueva identidad de las «universitarias».

En un contexto social en el que se abrían tímidas brechas en el modelo de feminidad doméstica, la JUF dio difusión a los discursos y actuaciones de estas mujeres profesionales preparadas intelectualmente que, a partir de 1928, acrecentaron su participación socio-política, demandando también derechos femeninos igualitarios.

De esta manera, mediante estructuraciones lingüísticas y nuevas prácticas y experiencia de vida, la JUF preparó a un minoritario sector de universitarias para que se constituyeran en una élite rectora del proceso emancipador, que paulatinamente se dotó de autoridad en la vida pública. Igualmente, estableció alianza con otros grupos feministas y con grupos mixtos de estudiantes para difundir el modelo de identidad que se atribuían y para consensuar reivindicaciones respecto a una ciudadanía femenina más plena, ciudadanía que se consolidarían en parte durante la II República.
\end{abstract}

Palabras clave: género, domesticidad, identidad, significados culturales, ciudadanía. 


\begin{abstract}
This article analyses the way the Juventud Universitaria Femenina (JUF) was set up in 1920, just a few years after women were allowed to take higher studies in Spain,with the main aims of building and giving meanings to the new identity of «female university students».

In a social setting in which some tinycracks were being made in the model of household femininity, the JUF disseminated the discourse and action taken by these intellectually trained professional women who, from 1928, extended their social-political participation, also demanding equal rightsfor women.

By forming linguistic structures and with new life experience and practices, this was how the JUF trained a minority sector of university women to become anelite guiding the emancipation process, which gradually took on authority in public life. It similarly established an alliance with other feminist associations and with mixed groups of students to spread the identity model that they assigned themselves and in order to reach agreements on claims in respect of a more widespread group of female citizens, citizens who would partly become consolidated during the $2^{\text {nd }}$ Republic.
\end{abstract}

Keywords: gender, domesticity, identity, cultural meanings, citizens. 


\section{Introducción}

Las distintas estrategias del feminismo histórico en España se vehiculizaron, como afirma Mary Nash, entre lógicas de género y lógicas políticas que se fundamentaban en distintos argumentos en torno a lo público y lo doméstico, con el objetivo de ampliar los márgenes de la feminidad y reclamar derechos sociales y políticos para las mujeres.

La imposición de una rígida noción que separaba lo público de lo privado constituía, en los inicios del siglo veinte, el eje vertebrador del discurso de la domesticidad que otorgaba valores concretos a una correcta conducta femenina e imponía normativamente a las mujeres que su destino legítimo era el hogar. Por esta razón, los discursos y prácticas feministas tuvieron que cuestionar de manera abierta o implícita el contrato de género y afirmar la aportación de las mujeres en otras parcelas de la sociedad $^{1}$.

En este proceso, los feminismos de distinto signo tuvieron, además, que conformar nuevas representaciones mentales y simbólicas del mundo y de la realidad, representaciones capaces de modelar comportamientos e influir en las elecciones particulares de las mujeres de forma que dieran nuevos significados a sus experiencias de vida ${ }^{2}$. Así pues, junto al sustrato reivindicativo y a la protesta, fue necesario estructurar discursos, categorías y simbolizaciones a través de las cuales la población femenina aprehendió formas más autónomas de entender y vivir las relaciones entre los géneros.

En consecuencia, en el progresivo tránsito de las mujeres hacía la esfera pública cabe valorar la acción social del movimiento feminista incidiendo también en su capacidad para construir significados culturales que dieran sentido y legitimidad a nuevas prácticas femeninas, ya que como afirma Francisco Cobo «los individuos (particularizadamente o de forma colectiva), tan solo acceden a entender los entresijos de sus vivencias materiales y de sus experiencias a través de la ayuda que les proporcionan las construcciones simbólicas y las representaciones mentales de la realidad disponibles para todos ellos» ${ }^{3}$.

1 Nash, 2012, p. 18.

2 Sobre las herramientas culturales, su importancia en la forma de actuación de los movimientos sociales, véase, White, 1999, pp. 319-324.

${ }^{3}$ Cobo, 2007, p. 83 
En esta línea de argumentación, este trabajo se propone interpretar la acción socio-cultural de la Juventud Universitaria Femenina (JUF) cuyos objetivos se centraron, en una primera instancia, en demandar igualdad de oportunidades para las jóvenes en las aulas y en los espacios académicos, pero también en difundir nuevos modelos de identidad basadas en el reconocimiento de la autoridad femenina en los ámbitos científicos e intelectuales. Identidades que, como afirma Alessandro Pizzorno, podemos entender como identificaciones compartidas en determinados círculos de reconocimiento, en los cuales los sujetos actúan y acaban reconociéndose como parte de un «nosotros» que los define ${ }^{4}$. Así pues, las universitarias de la asociación tuvieron, no sólo que cursar carreras con aprovechamiento y conquistar el espacio universitario negado históricamente a las mujeres, sino también tuvieron que reconfigurar una identidad femenina «moderna», la de la «universitaria», aprovechando los cambios que acompañaron la Primera Guerra Mundial y el conjunto de fenómenos asociados a ella, donde como afirma Nerea Aresti, proliferaron los «discursos destinados a redefinir la feminidad y la masculinidad», en un clima social de quiebra de las certezas en el terreno de las relaciones entre hombres y mujeres, necesidad de recuperación de las certidumbres y reformulación de la diferencia sexual, «en términos más renovadores unas veces y menos en otras $»^{5}$.

Con el paso del tiempo, en torno a 1928, las actuaciones de la JUF sumarían a sus discursos en pro del reconocimiento de la igualdad intelectual de las mujeres, un mayor compromiso social y la demanda del sufragio y de otros derechos civiles y políticos para las mujeres ${ }^{6}$. Así también, es propósito de este estudio interpretar la forma en que paralelamente a los avances en la construcción de identidades femeninas progresivamente relacionada con el estudio o ejercicio de carreras y profesiones universitarias, la JUF, que posteriormente pasó a denominarse Asociación Universitaria Femenina ${ }^{7}$, activó una serie de redes de relación con organizaciones de mujeres y con asociaciones estudiantiles mixtas con el propósito de difundir y afianzar el modelo de identidad que promovían, pero también se propuso ampliar sus márgenes representacionales reclamando el derecho de todas las mujeres a acceder a una ciudadanía plenamente igualitaria.

${ }^{4}$ Pizzorno, 1989, p. 39.

5 Aresti, 2012,pp. 55, 57, 58 .

${ }^{6}$ Magallón, 2014, p. 84.

${ }^{7}$ La asociación ha sido también estudiada por Fagoaga, 1985, p. 143-152 y Crespo, 1990. 
Lo que significa que el objetivo de este texto es también analizar la conformación histórica de las identidades de género en su carácter contextual, variable y múltiple que se desarrolla en un proceso continuo de construcción y redefinición cultural ${ }^{8}$.

\section{Antecedentes e intenciones}

La Institución Libre de Enseñanza (ILE), desde finales del siglo XIX, se había comprometido a auspiciar un modelo de educación que potenciase que niñas y jóvenes se educaran en todos los grados de igual forma y junto con los niños, aunque manteniendo también los tradicionales aprendizajes femeninos como resorte fundamental «para acabar con la [...] inferioridad positiva de la mujer» ${ }^{9}$. Desde estos planteamientos, iniciativas como la constitución de la Junta de Ampliación de Estudios en 1907, de la Residencia de Señoritas en 1915 o del Instituto-Escuela en 1918, favorecieron la incorporación de un minoritario grupo de mujeres jóvenes a la formación intelectual, de forma que pudieron acceder al ámbito universitario en unas condiciones de relativa igualdad educativa respecto a sus compañeros varones ${ }^{10}$. Shirley Mangini matiza, sin embargo, que reconociendo la acción positiva de la ILE, en el contexto cambiante de las primeras décadas del siglo XX, manifestó también sus limitaciones puesto que niñas y jóvenes contaban con menos recursos y medios de los dedicados a los varones en los organismos que dicha institución regentaba ${ }^{11}$. Además, pese al reconocimiento legal para cursar estudios universitarios que había supuesto para las mujeres la Real Orden de 8 de marzo de 1910, las primeras universitarias tuvieron que superar múltiples obstáculos sociales, como la imagen negativa que recaía sobre ellas, la necesidad de contar con el permiso familiar para matricularse, el requerimiento de acudir acompañadas a las aulas o el tener que sentarse en sitios especiales. También, se enfrentaron a trabas para la expedición de títulos, para la colegiación o en el propio ejercicio profesional ${ }^{12}$.

8 Rose, 2012 y Scott, 2008.

9 Xirau, 1969, p. 46.

10 Sobre el desarrollo de las citadas instituciones en relación con las mujeres, véase Vázquez, 2012.

11 Mangini, 2001, p. 54-55.

12 Flecha,1996. 
Por esta razón, en 1919, la decisión de la Asociación Nacional de Mujeres Españolas (ANME) de auspiciar la creación de la JUF, puede entenderse en la lógica de elaborar aprendizajes femeninos que complementando y promoviendo la preparación intelectual de sus asociadas, alentaran mayores cuotas de equidad respecto a las mujeres y ciertas rupturas con las normas de género. La creación de la nueva organización pone de manifiesto asimismo, la voluntad de una parte del feminismo hispano de extender su influencia social, comprometiendo a las jóvenes universitarias que cursaban o habían cursado carreras superiores en la defensa de sus intereses como estudiantes y profesionales ampliando, de este modo, los prototipos de feminidad de la época. No hay que olvidar que por esos años en Inglaterra y Francia emergían figuras femeninas «modernas» que representaban una nueva generación de jóvenes, con frecuencia de clases acomodadas, que habían recibido una sólida educación y compartían aspiraciones profesionales ${ }^{13}$.

En torno a esos años, la ANME, pese a su minoritaria militancia, defendía el sufragio y la igualdad, promovía leyes no discriminatorias para las mujeres en el ámbito familiar, exigía que se reconocieran para ellas nuevas profesiones, propugnando, además, el acceso femenino al mercado laboral y solicitando el «Apoyo y excitación al estudio de la Medicina de la mujer», el «Apoyo de los estudios de practicante o dentista» o que «en los centros docentes particulares [fueran] exigidos títulos pedagógicos a las profesoras» ${ }^{14}$. Desde esta lógica, en los meses de preparación para poner en marcha la JUF, la médica Elisa Soriano Fischer ${ }^{15}$ que fue su primera presidenta, hacía un llamamiento a estudiantes, licenciadas y doctoras a través de la revista La Medicina Social Española, instando a implicarse en la nueva asociación para «demostrar al mundo que la mujer española [era] tan digna como la de los demás países de la consideración universal» ${ }^{16}$. Esta demanda de modernización y apertura de horizontes enlazaba también con el auge que estaba experimentando la presencia de las mujeres en las universidades en los países occidentales de nuestro entono.

13 Aresti, 2012, pp. 57-58.

14 Espinosa, 1975, pp. 193-200.

15 Elisa Soriano estaba por esas fechas recién doctorada en medicina a la edad de 29 años y contaba con cierto reconocimiento como oftalmóloga en la Real Politécnica del Socorro. «Noticias Varias», El Siglo futuro, 14 de octubre de 1919, p. 3.

16 Elisa Soriano Fischer, «La mujer ante los acontecimientos sociales», La Medicina Social Española, 5 de enero de 1919, pp. 25-26. 
Finalmente, la asociación se constituyó en Madrid el 7 de marzo de $1920^{17}$, trás los contactos que estableció la ANME con otras organizaciones feministas como la Liga Española para el Progreso de la Mujer, Acción Femenina o alguna Agrupación Femenina Socialista, que colaboraron dando a conocer el proyecto entre las estudiantes de las diferentes universidades españolas. Concha Fagoaga pone de manifiesto esta estrategia en la que, desde Valencia a través de la revista Redención o en Barcelona través de $L a$ Voz de la Mujer, se instaba a las jóvenes universitarias a organizarse y a «entregar el espíritu y la voluntad en la defensa y mejoramiento de todas las mujeres, sus hermanas $[\ldots]{ }^{18}$. Desde esta perspectiva, es posible afirmar que fue iniciativa de una parte del minoritario feminismo nacional actuar coordinadamente, pese a sus diferencias de matices, en aras de conformar un sujeto colectivo «feminista» capaz de aliarse, promover reivindicaciones y plantear estrategias comunes en función de sus propios intereses ${ }^{19}$. Intereses centrados, también, en ganar para su causa a esas jóvenes que desde 1910 estaban accediendo a los estudios superiores, de forma que se convirtieran en una minoría rectora del proceso emancipador. O como las mismas impulsoras de la JUF afirmaban, se trataba de encuadrar al «elemento intelectual femenino en relación con el feminismo para lograr que las futuras clases directoras de esta obra tan transcendental est[uvieran] integradas por mujeres de superior educación y cultura» ${ }^{20}$.

De forma coincidente, como ya se ha señalado, tras la Primera Guerra Mundial, Europa vivía un contexto favorable para plantear debates y remover obstáculos respecto a la tradicional división sexual de papeles entre hombres y mujeres que afecto tanto a los partidos políticos socialistas y comunistas, como a los sectores católicos, dado que el papa Benedicto XV aprobó también la participación activa de las católicas en la política y dio su consentimiento velado al voto femenino ${ }^{21}$. A ello hay que sumar también el auge que adquiere la constitución de movimientos juve-

17 «Juventud Universitaria Femenina», La Libertad, 2 de septiembre de 1921, p. 6. El domicilio de la asociación estaba ubicado en la calle de Fuencarral, 53, segundo, de Madrid.

${ }_{18} \mathrm{La}$ autora hace referencia a: «La Juventud Universitaria Feminista», Redención, abril y mayo de 1920. Fagoaga, 1985, pp. 144, 150, 151.

19 Valcárcel,1997, p. 91.

20 «Asociación Nacional de Mujeres Españolas», El Globo, 3 de marzo 1920, p. 6.

${ }_{21}$ Me refiero a trabajos como los de Díaz Fernández, 2005, p. 179, y Eley, 2003, pp. 102-113. 
niles progresivamente autónomos ${ }^{22}$ que se solaparon con la conformación de esta nueva identidad de género, el de la «Mujer Moderna», que si bien seguía dependiendo de los tradicionales roles femeninos, maternales y domésticos, abría para las jóvenes mayores oportunidades en el campo político, laboral, artístico y cultural, dotándolas de cierto reconocimiento en la esfera pública ${ }^{23}$. De la evidencia de esta conjunción da muestra el artículo de Mary Luz Utrech en la sección «Vida Joven» del diario La Libertad, cuando exhortaba a sus lectoras con las siguientes palabras: «iÁnimo compañeras mías! A estudiar para procurar ser buenas compañeras del hombre y ese modelo nuevo de mujer que la sociedad necesita ${ }^{24}$.

\section{Emergencia y difusión de un nuevo modelo identitario}

En este clima de ciertas transformaciones respecto a las atribuciones femeninas después de la Primera Guerra Mundial, la JUF se constituyó como una asociación intergeneracional con militantes que gozaban de cierto renombre y prestigio profesional como la médica Concepción Alexandre, la maestra y pedagoga María de Maeztu o Clara Campoamor que realizaba por entonces estudios de Derecho, pero también, como pone de manifiesto la composición de su Junta Directiva en $1922^{25}$, de estudiantes, recién licenciadas y doctoras que en años posteriores alcanzarían relevancia social en la sociedad española como fueron entre otras Elisa Soriano, Rosario Lacy, Matilde Huici Navaz, Jimena Quirós y FernándezTello o Victoria Kent ${ }^{26}$.

En cualquier caso, la actividad de la asociación centró una parte importante de sus actuaciones en respaldar a las 340 estudiantes que en 1920, cursaban carreras superiores y que constituían tan sólo el 1,5\% de matrículas femeninas frente al 98,5\% que correspondían a los varones ${ }^{27}$, en un ambiente social en el que las universitarias, como afirmaba María

22 Souto Kustrín, 2007, pp. 171-192.

${ }^{23}$ Sobre la «Mujer Moderna» pueden consultarse los trabajos de Aresti, 2001; Nash, 1993 y Luengo, 2008.

${ }^{24}$ Mary Luz Utrech, «La mujer va despertando», La Libertad, 9 de junio de 1928, p. 2.

25 Cristóbal De Castro, «Las mujeres. Juventud Universitaria Feminista», Nuevo Mundo, 10 de marzo de 1922, p. 25.

26 Poveda, 2013, p. 230-231.

27 Montero, 2010, p. 158. 
de Maeztu, estaban siendo «bien acogidas en la vida pública», aunque seguían teniendo ciertas dificultades para realizar sus estudios y en la vida laboral «recib[ían] salarios más bajos que los hombres» o encontraban impedimentos para ejercer sus profesiones ${ }^{28}$. Por esta razón en los estatutos de la asociación se hacían explícitas sus reivindicaciones igualitarias al demandar que se otorgase a las jóvenes «los derechos que les corresponden y que al estudiar una carrera pu[dieran] obtener los mismos puestos que los hombres cuando por su inteligencia lo mere[cieran] $\gg^{29}$.

Para llevar a término estos propósitos de defensa y promoción de sus asociadas y de conformación de un nuevo modelo cultural de género, la JUF convocaba periódicamente premios y becas de estudio que ofrecían a las estudiantes la posibilidad de mejorar su rendimiento académico y realizar estudios en el extranjero. La prensa daba publicidad a estas iniciativas, anunciando pagos de matrícula o concesión de becas para las universitarias, afirmando que el procedimiento de selección se haría por «concurso de méritos» y valorando el expediente académico. En otros anuncios, se señalaba que los premios y becas no contaban con subvención estatal y se promovían con la intención de «contribuir de algún modo a que se acrecienten las inclinaciones de las estudiantes a cursar estudios universitarios $»^{30}$.

En relación con la International Federation of University Women (IFUW) de la que formaba parte desde 1921, la JUF participaba además en el programa de Becas Internacionales de Intercambio. Becas que ponían de manifiesto la capacidad de las redes internacionales de mujeres universitarias de gestionar y promover estancias de estudiantes y profesoras en centros de investigación extranjeros mediante «pensiones para estudios» $\mathrm{o}$ «intercambios de profesores de enseñanza secundaria» que favorecían «la difusión cultural a la que todos los pueblos aspiran» ${ }^{31}$. Valga citar como ejemplo que en 1928, la IFUW convocó cuatro becas, una, para

${ }^{28} \mathrm{La}$ autora hace referencia al informe elaborado por María de Maeztu, para el Congreso Internacional de Doctoras, celebrado en Londres en 1920. Crespo, 1990, p. 15.

29 «uventud Universitaria Femenina», Redención, abril, mayo de 1921.

30 «Juventud Universitaria Femenina», La Libertad, 2 de septiembre de 1921, p. 6. Valga citar como ejemplo que en el curso de 1920-21 las beneficiarias de becas fueron «las señoritas Sejudo Hervás, de Ciencias» y «la señorita Rosa Poy, de Odontología» y, en el curso de 1921-22: «Juana García Orcollen, de Medicina» y «Mercedes García López, de Ciencias Naturales».

31 «a Asociación Internacional de Universitarias. Consejo en Madrid», La Esfera, 15 de septiembre de 1928, p. 2. 
visitar laboratorios y museos en Francia que estaba dotada de 2.000 francos, otra de la Asociación Americana «para realizar estudios en cualquier país extranjero» y cuyo importe ascendía a 1.500 dólares, y otras dos becas para el Girton College de Cambridge con la finalidad de realizar investigaciones durante tres años, en el campo científico o de las letras y las artes, a razón de 300 y 250 libras por año ${ }^{32}$.

La IFUW se había fundado en Londres en 1919 tras el final de la guerra, con los objetivos de establecer relaciones de amistad y colaboración internacional entre las mujeres universitarias por medio de intercambio de alumnas, ex alumnas y profesoras y, también, para promover la educación femenina y fomentar la representación de las universitarias en los organismos internacionales, con la finalidad de «estimular la plena aplicación del talento de las socias a los problemas que se presenten en todos los órdenes de la vida pública ${ }^{33}$. Igualmente, trataban de trabajar por la paz sin distinción de raza, nacionalidad, religión u opciones políticas, lo que significaba también colaborar con la naciente Liga de Naciones. De hecho Virginia Girdersleeve, una de las fundadoras de la IFUW, fue la única representante femenina en la delegación norteamericana que en 1945 asistió a la Conferencia de San Francisco donde se firmó la Carta de las Naciones Unidas» ${ }^{34}$. Desde esta lógica, la JUF impulsó y colaboró en la fundación de la Liga Femenina Española por la Paz en España, en cuyas filas se integraron muchas de sus militantes, cediendo sus locales para las reuniones. La española María Palancar, licenciada en Derecho, ocupó años más tarde, un puesto en la Liga de Naciones ${ }^{35}$.

Con la intención también de difundir una imagen de valor y autoridad femenina que se atribuían las universitarias, la JUF contaba en sus actos de entrega de becas con la presencia de autoridades políticas o académicas como por ejemplo, el ministro de Instrucción Pública ${ }^{36}$ o con el decano de la Facultad de Filosofía y Letras que dirigió «breves palabras de aliento a las señoritas de la Asociación y dedicó un sentido recuerdo a la condesa de Pardo Bazán, catedrático de la Universidad» ${ }^{37}$. Esta idea de reconocer personalidades femeninas relacionadas con la ciencia, pero también

\footnotetext{
32 «Asociación Universitaria Femenina», El Sol, 25 de diciembre de 1928, p. 12.

33 Crespo, 1990, p. 30.

${ }^{34}$ Sasiain, 1996, p. 15.

35 Crespo, 1990, p. 24.

36 «Noticias y sucesos», El Sol, 11 de noviembre de 1922, p. 9.

37 «Juventud Universitaria Femenina», La Acción, 23 de Mayo, 1921, p. 2.
} 
de acercar la asociación a las instituciones y a figuras masculinas relevantes en la vida universitaria y política se constata asimismo en el hecho de que una Comisión de la asociación con Elisa Soriano a la cabeza mantuvo una audiencia «con Su Majestad» ${ }^{38}$ con la finalidad de darle a conocer su labor y los fines que perseguían. Con estas iniciativas de solvencia y activismo, la labor de la JUF era tachada de «admirable» por Cristóbal de Castro en la revista Nuevo Mundo, puesto que frente a otros proyectos feministas de «arrugas culturales y canas morales», la Juventud Universitaria Femenina «auna[ba] la actividad juvenil y la gravedad estudiosa, la inquietud espiritual y el método científico» ${ }^{39}$.

De este modo, mientras que en la sociedad española, como ya se ha señalado, tenían lugar amplios debates sobre la modernización o no de los discursos y atribuciones de género ${ }^{40}$, la JUF promocionaba también una identidad femenina relacionada con los saberes y ponía en marcha además nuevas formas de conocimiento autorreferencial, lo que actualmente denominaríamos estudios con perspectiva de género, cuyos objetivos se centraban en la reflexión académica sobre las propias mujeres. Y para ello, subvencionaba investigaciones en torno a la situación de las jóvenes en las instituciones académicas, a través de un concurso científico-literario «para fomentar el estudio del trabajo de la mujer universitaria, sea cual sea la Facultad á que dedique sus actividades ${ }^{41}$. En otros casos, programaba Conferencias y Jornadas, como las que tuvieron lugar en 1922, entre febrero y mayo en la Universidad Central de Madrid, como espacio de debate y visibilización de las universitarias, en la que se alternaba la presencia femenina y masculina en la tribuna en una equilibrada y precoz paridad. En esa serie de 13 disertaciones, la mayoría de ellas centradas en las funciones sociales de las mujeres, intervinieron figuras relevantes de la vida académica y cultural como la «escritora» Clara Campoamor que habló de «La mujer en el nuevo ambiente», la doctora en Letras Pilar Oñate, cuya contribución llevaba por título «Feminismo en la Literatura española» y Odón de Buen y Tomás Montejo que disertaron sobre, «La mujer

38 «La Familia Real», La Acción, 4 de octubre de 1921,p. 2.

39 Cristóbal De Castro, «Las mujeres. Juventud Universitaria Feminista», Nuevo Mundo, 10 de marzo de 1922, p. 25.

40 Aresti, 2001.

41 Cristóbal de Castro, «Las mujeres. Juventud Universitaria Feminista», Nuevo Mundo, 10 de marzo de 1922, p. 26. 
en la Universidad»y «La mujer ante el Derecho positivo español», respectivamente ${ }^{42}$.

Por esa mismas fechas, revistas como La Esfera publicaban periódicamente informaciones en las que se hacía mención a la armonía reinante en el quehacer profesional y familiar de las mujeres universitarias que conformaban la asociación como Concepción Aleixandre, Rosario Lazy, la doctora Pérez-Rama, la doctora Márquez, Pilar Oñate o Matilde García del Real, porque además de triunfar en sus carreras, de las que se hacían breves crónicas, compartían matrimonio con varones que constituían también nuevos modelos de masculinidad, ya que como afirmaba María Valero, «el hombre civil no se asusta de las mujeres cultivadas, y en esta cultura saben disfrutar todas las seguridades del amor recio y fuerte ${ }^{43}$.

En última instancia, la JUF, en los primeros años de su constitución, ofrecía un repertorio de discursos y experiencias que delimitaban la nueva identidad de las «universitarias» a través de imágenes de saber y autoridad femenina, de ritos y actuaciones como los de ocupar las tribunas en las instituciones académicas o aparecer en la prensa, y de múltiples dispositivos simbólicos que invitaban a la identificación y legitimaban la presencia y el valor de las nuevas estudiantes, licenciadas y doctoras en los espacios universitarios y en la sociedad, poniendo de manifiesto además, que gozaban de relaciones de género en los foros científicos y universitarios y en la institución familiar, más equitativas y acordes a los nuevos tiempos.

\section{Alianzas y nuevos protagonismos de las «universitarias»}

En este proceso de elaboraciones discursivas y prácticas experienciales y simbólicas capaces de dar sentido e inteligibilidad a sus actuaciones, la JUF canalizó una parte de las aspiraciones individuales y colectivas de sus militantes, como ya se ha mencionado, a través de la International Federation of University Women que realizaba periódicamente encuentros científicos como el Congreso Internacional de Doctoras de Londres, en 1920, el Congreso Internacional de Estudiantes, de Praga, en 1921 y en el Internacional de Estudiantes, de Montpellier, en 1922, al que asistieron

42 Ibídem, p. 26.

43 María Valero de Mazas, «Mundo Femenino. Las Juventudes Universitarias», La Esfera, 17 de Julio de 1920, p. 17. 
representantes españolas. En estos encuentros internacionales se debatía la situación de las universitarias y estudiantes en el ámbito de la ciencia y de las instituciones académicas, planteándose tareas y objetivos comunes y manifestando una imagen de solvencia y de rigor. Con motivo de la celebración del Congreso de Praga, fue Victoria Kent, por entonces estudiante de Derecho, la que emergía en la escena pública en su calidad de delegada de la JUF y con este motivo ofreció la asociación una charla en el Ateneo de Madrid, en la que ella afirmó que «e[ra] la primera vez que habla[ba] en público» y que su presencia en el Congreso de estudiantes era representar a la asociación para abundar en los ideales de «mejoramiento y engrandecimiento de la mujer española» ${ }^{44}$.

Pero, además, la JUF erigida en agencia de representación de «las universitarias» españolas desplegó sus acciones operativas y movilizadoras con otras organizaciones mixtas como la Asociación de Estudiantes Hispanoamericanos y con la Unión Nacional de Estudiantes ${ }^{45}$, organización esta última próxima a la Institución Libre de Enseñanza, en un ambiente especialmente proclive a la movilización estudiantil tras la aprobación del Real Decreto de 21 de mayo de 1919 que regulaba y ampliaba la participación del alumnado en la vida universitaria, incluyendo la elección de cargos docentes ${ }^{46}$. Estas alianzas se prolongarían a lo largo del tiempo contribuyendo a establecer vínculos de apoyo mutuo y trabajo común, lo que en última instancia normalizaba, en cierto modo, la colaboración igualitaria entre estudiantes de ambos sexos. De hecho, en una acto del que la prensa daba cumplida cuenta, la JUF que contaba con una nutrida y bien dotada biblioteca abierta a la consulta pública, puso este recurso a disposición de la Federación Universitaria Hispanoamericana, nacida en el seno de la Universidad Central de Madrid ${ }^{47}$, aportando a los fondos de la citada federación 2.000 volúmenes para crear una biblioteca circulante $^{48}$. En este punto cabe mencionar que los movimientos sociales, en el camino de difundir sus demandas y consolidar nuevos modelos identitarios, cuentan con otros grupos y sectores afines que reconocen las nuevas identidades que se atribuyen y contribuyen a difundir sus proyectos.

44 Ramos, 1998.

45 «Juventud Universitaria Feminista», España Médica, 20 de diciembre de 1921, p. 15.

46 Barba, 1999, p. 120.

47 Carreño, 2013.

48 «Los nuevos estudiantes», La Esfera, 21 de julio de 1928, p. 35. 
Es lo que los estudiosos de la acción colectiva denominan la difusión por coalición social ${ }^{49}$.

El desarrollo de estas redes asociativas estudiantiles en España, en las que participaba la JUF, experimentaron en torno a 1928, con la dictadura de Primo de Rivera, un significativo desarrollo, dado que, como afirmaba el presidente de la Federación Universitaria de Escolar (FUE) de Madrid, «urg[ía] acercar la enseñanza superior al pueblo» ${ }^{50}$. En otros casos, dicha Federación hacía explícito que entre sus objetivos se contaba el de implicar al alumnado «educándolo en una escuela de ciudadanía y de disciplina que forzosamente [debía] formar generaciones más aptas» ${ }^{51}$. Eduardo González Calleja y Sandra Souto Kustrín dan cuenta también del ascenso que experimentó el asociacionismo juvenil en España, señalando que a nivel historiográfico es precisamente la rebeldía estudiantil de finales de los años veinte, una de las cuestiones más tratadas ${ }^{52}$.

Esta nueva cultura en el ámbito del estudiantado, que como afirma Eduardo González Calleja estaba «centrada en la crítica a las instituciones que, como la familia, la Iglesia o la escuela, eran los puntales de la sociedad conservadora y se especializaban en la transmisión de una cultura del establishment» (González Calleja, 2005, p. 32), otorgaba cierta presencia y legitimidad a las actuaciones de las universitarias. En este mismo sentido cabe apuntar que como señala Shlomo Ben-Ami, las nuevas generaciones de estudiantes estaban desarrollando una cultura propia que incluía una reacción colectiva contra los procesos de socialización autoritaria y patriarcal que implicaba también cuestionar las posiciones de las mujeres en la sociedad (Ben-Ami, 1979, p. 373). Por esta razón, las asociaciones del movimiento estudiantil a las que se ha hecho referencia, compartían un conjunto de creencias y acciones colectivas contrarias a la sociedad tradicional y a las institucciones que la sustentaban y rompían con ciertos límites del sistema de normas dando lugar a un mundo social de visos modernizadores que contribuía también a construir modelos de masculinidad y feminidad más equivalentes.

49 Tarrow, 2004, pp. 85-86.

50 Antonio María Sbert, «Universitarias», La Libertad, 9 de junio de 1928, p. 9.

51 «a vida estudiantil. La Federación Universitaria Escolar de Madrid», La Libertad, 31 de julio de 1928, p. 5.

52 González Calleja, y Souto Kustrín, 2005, pp. 283-298; Moreno Seco y Ortuño Martínez, 2015. 
Como ejemplos, cabe señalar que Clara Campoamor, Elisa Soriano, Gimena Quirós y Matilde Huici como representantes de la JUF, se reunieron con José Castillejo, Secretario de la Junta para la Ampliación de Estudios y con otros miembros de la FUE, para solicitarle colaboración en la puesta en marcha del XII Congreso de la International Federation of Women University que se iba a celebrar en España, pedirle la actuación de los coros de la FUE en el acto y tratar el tema de la enorme fuerza que habían adquirido las instituciones estudiantiles en el extranjero ${ }^{53}$. Igualmente, en los actos de presentación del amplio programa que la JUF se proponía desarrollar en 1928, centrado en lo «cultural, social y la ayuda mutua», que tuvo lugar en la Delegación Municipal de la Universidad, junto a la señora San Martín y las señoritas Campoamor y Quirós, se señalaba la presencia de Conrado Espín, periodista, y miembro de la Asociación Española de Escritores y Artistas Noveles y Masera ${ }^{54}$. Más significativo resulta el hecho de que en la inauguración del nuevo local de la asociación, ubicado en la Carrera de San Jerónimo, 58, piso bajo, de Madrid, se mencionan los apellidos de algunas de las «señoritas que asistieron» al acto, como Campoamor, Huici, Sánchez, Calvo Peña, Soriano, etc. sin que constase ninguna asociación femenina, aunque sí un buen número de representantes de organizaciones estudiantiles mixtas como la FUE, la Asociación de Alumnos de Ingenieros y Arquitectos, la Federación Universitaria Hispanoamericana o la Asociación de Estudiantes de Derecho ${ }^{55}$.

Por estas mismas fechas, y pese a la estrecha colaboración de la JUF con ciertas asociaciones estudiantiles mixtas, en los ambientes universitarios seguía vigente el temor de algunos hombres a la penetración de las mujeres en las aulas universitarias argumentando que el desarrollo de su vida laboral en diversos campos restaría puestos de trabajo a los hombres $^{56}$. Es por ello que, en este clima de pugna cultural y de convivencia de distintas mentalidades que debatían respecto a la idoneidad, o no, de que las mujeres ejercieran carreras, el XII Congreso de la International Federation of University Women, que tuvo lugar en España el 15 de fe-

53 «Juventud Universitaria Femenina», La Libertad, 9 de junio de 1928, p. 10.

54 «Asociación Universitaria Femenina», La Época, 20 de noviembre de 1928, p. 8.

55 «Asociación Universitaria Femenina», Heraldo de Madrid, 21 de febrero de 1929, p. 7.

${ }^{56} \mathrm{La}$ autora hace referencia a varios artículos publicados en 1926, en la revista Renovación española. Montero, 2009, p. 321. 
brero de $1928^{57}$, se planteó como un ejercicio de afirmación de la identidad que hemos denominado de «la universitaria», una identidad que se difundió ampliamente en publicaciones como Mundo Gráfico, Estampa o La Esfera y en diarios como La Voz, Época o El Heraldo que incluyeron en sus páginas fotografías de las participantes, resúmenes de sus conferencias y breves reseñas biográficas donde se resaltaban los brillantes currículos científicos de las delegadas internacionales «[...] catedráticos, profesores de universidad o de Centros docentes de segunda enseñanza, las unas, miembros titulares de altos cargos político-administrativos o de profesionalidad en sus respectivos países» ${ }^{58}$. Los actos congresuales se organizaron en distintas localidades como Madrid, donde las actividades centrales tuvieron lugar en la Academia de Jurisprudencia, presididos por la Doctora Hellen Gledisth, presidenta de la IFUW. También hubo otros eventos en El Escorial, Sevilla, la universidad de Barcelona o Toledo, donde las delegadas fueron recibidas por rectores o representantes de los ayuntamientos y otros poderes públicos. Hubo asimismo un banquete oficial en el Hotel Palace que contó con la presencia de destacadas intelectuales europeas y americanas que pronunciaron diferentes discursos abundando en la necesidad de incorporar a las mujeres a la vida intelectual. Se cerró el acto con las palabras del conservador Ossorio y Gallado que alentaba a las mujeres al «mayor odio al convencionalismo» y las instaba a la «revolución en los conceptos y los modos». Intervino también en la clausura del banquete el ministro de Instrucción Pública ${ }^{59}$. En los relatos del Congreso, la prensa hacía referencia sistemáticamente a la Internacional Federation of University Women y a su doble objetivo de promocionar las aportaciones científicas femeninas y de contribuir al intercambio intelectual de las mujeres que desarrollaban una carrera universitaria en di-

57 La organización del Congreso corrió a cargo de la Junta Directiva formada por: Clara Campoamor como Presidenta, Loreto Tapia, María Barbán, Matilde Huici, Carmen Aldecoa, Encarnación Sánchez Herrero, Conrada Calvo, Concha Peña, Felisa Rodríguez, Josefina Soriano y Mercedes Tarancón. «Asociación Universitaria Femenina inaugura su nuevo local», La Nación, 21 de febrero de 1929, p. 4.

58 «La Asociación Internacional de Universitarias», La Esfera, 15 de septiembre de 1928, p. 8; «Congreso de la Federación de Mujeres Universitarias», Mundo Gráfico, 26 de noviembre de 1928, p. 14; «Las Mujeres Universitarias», La Voz, 22 de septiembre de 1928, p. 8; Estampa, 11 de septiembre de 1928, p. 11 y 12; Julio Ángulo, «El XII Congreso de Mujeres Universitarias», Época, 14 de septiembre de 1928, p. 2; «El XII Congreso de Mujeres Universitarias», El Heraldo de Madrid, 22 de septiembre de 1928, p. 9.

59 «Mujeres Universitarias», La Voz, 22 de septiembre de 1928, p. 3. 
ferentes países. En líneas generales, la representación de identidades femeninas que gozaban de una autonomía propia sin necesidad de recurrir a sus vínculos familiares, se perfilaba nítida en las palabras de Julio Ángulo cuando resumía las conclusiones del Congreso con las siguientes palabras:

«La idea hermosa del feminismo ha traído como consecuencia el reconocer los derechos de la mujer, tan importantes o más que los del hombre, en la sociedad. Ya no se limita a ser madre y esposa obediente, sino que la ley la autoriza para extender el vuelo de sus aspiraciones y lograr de ese modo una personalidad propia aparte del hombre. La mujer actual debe procurar ser la "doctora X" y no limitarse nunca a ser la "señora del doctor I" ${ }^{60}$.

En otros casos, como en el amplio reportaje titulado «El Feminismo en marcha. Las "abogados" de España están contentas de su profesión», publicado meses antes en la revista Estampa, se daba también a conocer a la opinión pública la labor de las primeras abogadas españolas que hablaban de su profesión y demandaban una mayor equidad entre los géneros en todos los ámbitos de la vida social. Así, Matilde Huici reivindicaba «que abogados y abogadas, $\mathrm{t}$ [tuvieran], al graduarse, los mismos horizontes: Registros de la propiedad, Consulados, Notarías, Judicatura...». Clara Campoamor «cre[ía] que el advenimiento de la mujer a la vida del Derecho tenía trascendencia sin igual para la futura igualdad económica, civil y social de los sexos...», mientras que Victoria Kent decía: «Mi profesión que no abandonaría ni por nada ni por nadie, me ha proporcionado las mayores satisfacciones de mi vida... ${ }^{61}$. De esta forma la emergencia de estas nuevas imágenes de mujeres universitarias traspasaba algunos límites de la domesticidad, dado que la instrucción superior y el trabajo profesional les permitía gozar de independencia personal y económica, de un proyecto de vida propio y de cierto reconocimiento social al margen de la vida doméstica y familiar. Cabe también matizar que, por esas fechas, un escaso número de 345 alumnas cursaba estudios universitarios en España ${ }^{62}$. Es decir, la presencia femenina en las uni-

\footnotetext{
60 Julio Ángulo: «El XII Congreso de Mujeres Universitarias», Época, 14 de septiembre de 1928, p. 2.

61 V.S.O, «El Feminismo en marcha. Los “abogados” de España están contentas de su profesión», Estampa, 21 de febrero de 1928, p. 19.

${ }^{62}$ Capel, 1982, p. 380.
} 
versidades era residual y por debajo de los países de nuestro entorno, ya que en los años 30, sólo el $6 \%$ de los estudiantes eran mujeres en nuestras Facultades, mientras en Francia el porcentaje era del 25.8\%, en Italia la media en los años 20 era del 14\%, en Alemania suponía el 16\% en 1931 y en Gran Bretaña, era del 27\%, en esas mismas fechas (Montero, 2009 , p. 323). Igualmente, la JUF no era una organización mayoritaria, y si bien en 1920 contaba con 100 afiliadas, en 1928 la cifra había descendido a 68 asociadas ${ }^{63}$. En este acusado descenso de militantes de la $J u$ ventud Femenina Universitaria, cabe valorar que por esas fechas las una parte de las estudiantes más comprometidas, probablemente escogieran militar en asociaciones estudiantiles mixtas como la FUE, ya que como señala José López-Rey, en torno a 1929, en los conflictos plateados por la ley Callejo, las «muchachas» universitarias mantuvieron una firme lucha contra la dictadura de Primo de Rivera que llevó a algunas de ellas a ser detenidas y encarceladas como sus compañeros varones ${ }^{64}$. Y, pese a que las organizaciones de estudiantes católicos no encuadraban más de un 5\% del conjunto del alumnado universitario, es plausible también que, otra parte de las jóvenes universitarias, se sintieran atraídas por el amplio movimiento femenino católico que se estaba poniendo en marcha a nivel nacional con el despegue de la Agrupación Nacional de Mujeres Españolas, fundada sobre la base de Acción Católica de la Mujer y del sector femenino de la Unión Patriótica ${ }^{65}$.

Pese a ello, en un contexto de cierto protagonismo social de algunas mujeres universitarias y con la llegada de Clara Campoamor a la presidencia de la Junta Directiva de la JUF, que ya se denominaba Asociación Universitaria Femenina (AUF) ${ }^{66}$, se inició una etapa de mayor activismo socio-político desplegando sus acciones en varios frentes complementarios. En el ámbito educativo y universitario la AUF organizó Comités de Facultad para apoyar y estudiar los problemas que encontraban las jóvenes estudiantes para la obtención del título ${ }^{67}$. También la asociación visitaba o requería al Ministro de Instrucción Pública para solicitar exámenes

63 Fagoaga, 1985, p. 151.

${ }^{64}$ López-Rey, 1930, pp. 235-245.

65 Arce, 2008, p. 159.

66 No se ha localizado ninguna explicación sobre el cambio de denominación de la asociación, aunque posiblemente la edad ya madura de muchas de sus afiliadas propiciara el abandono del término juventud y su sustitución por el de asociación.

67 Magallón, 2014, p. 84. 
extraordinarios en la Facultad de Farmacia ${ }^{68}$, la derogación de la ley de creación de Institutos Femeninos o que se «concediera libertad a los licenciados y doctores en derecho a presentarse a las oposiciones a cátedra de los Institutos de Educación Secundaria» ${ }^{69}$. Junto a las becas que continuaba otorgando la International Federation of University Women ${ }^{70}$, y con donaciones particulares y principalmente con las contribuciones del Vizconde Ezo, la AUF convocaba también bolsas de estudios, por ejemplo, «para conocer los fines, medios y orientación del Bureau International du Travail de Ginebra, especialmente todo lo relacionado a los trabajos de la mujer» ${ }^{71}$. Otras donaciones del mencionado Vizconde Ezo se destinaban a desarrollar actividades en las secciones de Ciencias y Letras y a organizar y promover en España una oficina internacional de trabajo dedicada a ayudar a las licenciadas universitarias a ejercer sus profesiones ${ }^{72}$.

En el ámbito social y asistencial, la AUF amplió su compromiso a otras mujeres no universitarias creando una oficina de mujeres trabajadoras que funcionó muy activamente. En el informe presentado por la asociación al Congreso Internacional de Ginebra de 1929 decían haber atendido 420 peticiones de empleo, para mujeres la mayoría, resueltas favorablemente $^{73}$. La iniciativa se inscribía en un contexto en el que los horizontes laborales y educativos habían ido mejorando discretamente para las mujeres desde comienzos del siglo Xx con una legislación que promovía el aumento progresivo de la escolarización de las niñas, de forma que, al menos teóricamente, nuevos campos laborales se abrían para las jóvenes en funciones administrativas y de servicios, mientras que el Estatuto de Funcionarios de 1918 les permitía también acceder a empleos en la Administración Pública ${ }^{74}$.

68 «En los Ministerios», La Época, 18 de noviembre de 1928, p. 4.

69 «Derogación de Institutos Femeninos», Crónica Meridional, 2 de marzo de 1930, p. 7.

70 A finales de 1929 seguían convocando becas para cursar estancias en Grosby Hall y en la Universidad de Girton, esta última institución era pionera en la educación de las mujeres. Otro ejemplo de becas en, «Asociación Universitaria Femenina», El Sol, 6 de diciembre de 1929, p. 6.

71 «Premios Vizconde Ezo», La Libertad, 14 de mayo, 1930, p. 7; El Sol, 14 de mayo, 1930, p. 2.

72 Crespo, 1990, p. 24.

73 Ibidem, p. 24.

74 Aguado y Ramos, 2002, pp. 114-116. 
Paralelamente, la AUF llevó también a cabo una campaña en la que ofrecían, en el local de la asociación, servicios médicos, jurídicos y sociales gratuitos a «la obrera» y «a la mujer sin ayuda ni apoyo», una campaña «a la americana» que difundieron con carteles que pegaron las militantes de la asociación en las calles como muestran algunas imágenes ${ }^{75}$ y en los que se podía leer:

«iiiProtección a la mujer desvalida!!!: las mujeres universitarias que tuvieron la fortuna de alcanzar un mejor nivel cultural con que embellecer su vida, consideran un deber entregar el espíritu, y la voluntad a la defensa y mejoramiento de todas las mujeres, sus hermanas» ${ }^{76}$.

La iniciativa se convirtió en un enfrentamiento abierto con el ayuntamiento de Madrid que se negó a dispensar a la asociación del impuesto preceptivo por cada cartel pegado. El altercado tuvo como consecuencia la detención por parte de la guardia municipal de varias universitarias a las que se les abrió «un atestado por desacato» por pegar carteles en la ca$11 \mathrm{e}^{77}$. En consonancia con esta campaña que tenía una clara implicación social, la doctora María Bardan ofrecía, en los locales de la asociación, una consulta prenatal gratuita los sábados de once a doce horas para «ayudar a las futuras madres en todo lo que se refiere a la fisiología de su estado y del futuro ser» ${ }^{78}$. Igualmente, a cargo de Clara Campoamor mantenían abiertos los servicios de «Orientación Social y Jurídica» y las socias de las Facultades de Farmacia y Ciencias programaban conferencias regularmente y la biblioteca a disposición del público estaba atendida por las estudiantes de la Facultad de Filosofía y Letras ${ }^{79}$. La campaña y los anuncios de los servicios que la AUF mantenía abiertos gratuitamente fueron ampliamente difundidos en prensa y bien recibidos incluso en algún diario conservador, porque como afirmaba Teresa de Escoriaza en Las Provincias, en contraposición a la impostura y a la frivolidad que ella consideraba que manifestaban las asociadas al Lyceum Club, refiriéndose a la AUF decía, «He aquí una institución que ha sabido enfocar de una forma

75 «Las mujeres en ayuda de las mujeres», Estampa, 26 de febrero de 1929, p. 41.

76 «Asociación Universitaria Femenina», La Libertad, 27 de febrero de 1929, p. 4.

77 Ibídem, p. 24.

78 «Asociación Universitaria Femenina», El Sol, 11 de julio de 1929, p. 3.

79 «Actualidad Femenina. Clara Campoamor y la Asociación Universitaria», El Imparcial, 3 de marzo de 1929, p. 3; Mundo Gráfico, 2 de octubre de 1929, p. 19. 
admirable su actuación», atendiendo verdaderamente a las mujeres que lo necesitan ${ }^{80}$.

En el ámbito civil y político Clara Campoamor y Matilde Huici enfocaron además los objetivos de la asociación en esta nueva etapa, demandando derechos jurídicos para mujeres y niños, como el establecimiento de la paternidad, la reforma del Código Civil en lo que hacía referencia al derecho de las mujeres casadas a disfrutar y disponer libremente de su salario. Denunciaron igualmente el artículo 438 del Código Penal y la injusticia que suponía que solamente contemplaba la pena de exilio al marido culpable de homicidio de su mujer sorprendida en adulterio, y que no imponía ningún castigo por las heridas que no causasen la muerte de la esposa o de su acompañante ${ }^{81}$. En colaboración con la Asociación Nacional de Mujeres Españolas y junto a otras organizaciones partidarias del sufragio como el Lyceum Club donde militaban muchas de sus socias, El Consejo Supremo Feminista y el Comité de Mejoras Sociales de Barcelona visitaron en mayo de 1930 al general Dámaso Berenguer, por entonces jefe del gobierno, para entregarle las siguientes peticiones: «Reconocimiento de la personalidad jurídica para la mujer casada; Conservación de la propia nacionalidad para la española, al contraer matrimonio con algún extranjero; Que la madre comparta con el padre la patria potestad sobre los hijos; Investigación de la paternidad; Que las causas de desheredación sean iguales para hombre y mujer; Que los emigrantes sean obligados, mediante sanción, a contribuir con sus ganancias al sostenimiento de la familia» ${ }^{82}$.

Era frecuente también que las abogadas Campoamor y Huici participaran en conferencias y estrecharan marcos de colaboración, aun cuando partían de planteamientos y objetivos muy diferentes, con la Agrupación Femenina Socialista de Madrid, reivindicando los mencionados derechos que tendían a construir una identidad femenina relacionada con la igualdad legal y la ciudadanía plena, identidad que estaba en función de los intereses específicos de las mujeres pese a los distintos matices e ideologías que profesaban (Aguado y Sanfeliu, 2015, p. 67). Otros grupos feministas de diferente tendencia, como Acción Femenina, La Cruzada de Mujeres

80 Teresa de Escoriaza, «Institución femenina digna de apoyo», Las Provincias: diario de Valencia, 6 de diciembre de 1929, p. 10.

81 Crespo, 1990, p. 21.

82 A. de Mirabal, «Anuncios», Revista Católica de las cuestiones sociales, mayo, 1930, p. 62. 
Españolas o Unión de Mujeres Españolas mantenían por esas mismas fechas similares demandas, compartidas también con una parte de hombres y con algunos partidos políticos, demandas que finalmente coincidirían en gran medida con las reformas legislativas aprobadas por la II República en lo que hacía referencia específica a la igualdad de género y a los derechos políticos y civiles de la mujeres ${ }^{83}$.

De este modo, la AUF tras cuestionar de manera abierta o implícita el contrato de género que prescribía ámbitos segregados y excluyentes entre lo público y lo doméstico y tras avanzar en la reapropiación de los espacios reales y simbólicos de la universidad y de la ciencia, emprendía nuevas estrategias relacionadas con la construcción de identidades femeninas relacionadas con la capacidad de las mujeres de acceder en mayor medida al mercado laboral y constituirse como sujeto político con derecho a gozar de una ciudadanía plena, ya que como plantea Joan Scott, las identidades de género son una construcción cultural móvil y contextual que no preexisten a sus invocaciones y estrategias políticas ${ }^{84}$.

Valga citar como ejemplos que muchas de las jóvenes que habían constituido en 1922 la asociación, eran ya figuras conocidas y gozaban de un sólido reconocimiento profesional. Elisa Soriano era oftalmóloga, había sido médica de la Marina Mercante y fundadora de la Asociación de Médicas Españolas. La maestra María de Maeztu era directora de la Residencia de Señoritas, miembro del Centro de Estudios Históricos y había sido presidenta del Lyceum Club. Rosario Lacy era ginecóloga y profesora de Psicología en la Institución para la Enseñanza de la Mujer. Gimena Quirós y Fernández-Tello era pionera en el campo de la investigación oceanográfica y pesquera, y trabajaba para el Instituto Español de Oceanografía. También, la química Loreto Tapia, la médica María Barbán, la maestra y farmacéutica Conrada Calvo Tejero, la maestra Carmen Aldecoa, la abogada y militante de Acción republicanana Concha Peña Pastor, entre otras, eran conocidas entre determinados sectores de la opinión pública y ejercían sus profesiones con éxito. Igualmente, tanto Victoria Kent como Clara Campoamor y Matilde Huici aparecían con frecuencia en los medios de comunicación por su activismo en el campo del derecho y durante la II República ostentarían el cargo de diputadas.

\footnotetext{
${ }^{83}$ Sanfeliu, 2008, pp. 76-77, y Del Moral Vargas, 2012, pp. 369-370.

${ }^{84}$ Scott, 2006.
} 


\section{Conclusiones}

Las prácticas y experiencias de vida no pueden ser separadas del lenguaje y de los discursos que articulan su representación ${ }^{85}$. En este sentido, la JUF y posteriormente la AUF, se constituyó, en 1922, con el «objetivo principal de ayudar todo lo posible a las estudiantes españolas, deseando contribuir de algún modo a que se acrecienten las inclinaciones de dichas estudiantes a cursar los estudios universitarios» ${ }^{86}$. Pero, sus intenciones fueron también que las «universitarias» dada su mayor preparación intelectual se comprometieran con el feminismo y con la promoción de las mujeres que cursaban una educación superior, contribuyendo con ello a desmantelar, en cierto modo, las imágenes hegemónicas de la feminidad doméstica. Por ello, las prácticas y los discursos de la asociación se centraron en la promoción científica y académica de estudiantes, licenciadas y doctoras universitarias y, también, en la reivindicación de espacios de autoridad femenina en los ámbitos de los saberes y de la ciencia. Alianzas nacionales e internacionales con asociaciones de mujeres y mixtas, visibilidad en los foros universitarios, apelaciones y contactos con los poderes públicos o presencia en los medios de comunicación, hicieron posible también al minoritario grupo que constituía la JUF, difundir una nueva imagen de solvencia y autonomía de las mujeres con educación superior, a pesar de que el número de universitarias en España seguía siendo escaso y el nuevo ideal de mujer moderna era minoritario.

Años más tarde, en 1928, y dado que algunas de sus integrantes se habían constituido en referentes a nivel profesional y social, la asociación amplió los límites de su acción social y puso los conocimientos de sus integrantes a disposición de otras mujeres en los campos laborales, jurídicos, médicos y culturales y, junto a otras organizaciones feministas, acometió la defensa de más amplios derechos emancipadores. Los tintes reivindicativos y el mayor compromiso socio-político protagonizan esta nueva etapa de la organización, que no abandonó por ello sus objetivos primigenios.

Por ello se puede afirmar que en la etapa republicana, que queda al margen de los límites cronológicos de este trabajo, no sólo muchas de las mujeres que habían formado parte de la JUF y posteriormente de la AUF,

85 Díaz Freire, 2003, p. 64-65.

86 «La Asociación Universitaria Femenina», La Voz, 26 de febrero de 1929, p. 8. 
ocuparon cargos públicos y políticos relevantes y muchas de ellas fueron diputadas, sino también que el modelo identitario femenino que a nivel educativo promovió el nuevo régimen, basado en una sólida instrucción de las mujeres para que pudieran desarrollarse profesionalmente, aunque sin abandonar sus roles maternales, coincidió en gran medida con las propuestas que desde décadas anteriores ambas asociaciones habían venido demandando. Igualmente, las reivindicaciones de derechos civiles y políticos de su última etapa se incorporaron a la Constitución de 1931 abriendo para la población femenina amplias posibilidades de gozar de una ciudadanía más igualitaria.

En definitiva, y como se ha mantenido a lo largo del estudio, los sujetos sociales precisan de determinadas estructuraciones lingüísticas y simbólicas que den sentido a las acciones humanas. Como muestran las asociaciones femeninas universitarias investigadas, a lo largo de una década, su labor no sólo consistió en apoyar de una forma práctica a las jóvenes que cursaban estudios superiores, sino en potenciar también que se reconociera, en cierto modo, el potencial de la identidad que hemos llamado de «la universitaria» para contribuir al desarrollo científico, social y político nacional, abriendo brechas en los modelos normativos de feminidad doméstica.

\section{Fuentes}

Biblioteca Nacional. Hemeroteca Digital, «hemerotecadigital.bne.es/index.vm». Biblioteca VirTual de PRENSA HistóRICA, «prensahistorica.mcu.es». HeMEROTECA Municipal de MADRID.

Hemeroteca Municipal de Valencia.

\section{Bibliografía}

Aguado, Ana y Ramos, M. ${ }^{\text {a }}$ Dolores, La modernización de España (1917-1939), Madrid, Síntesis, 2002.

Aguado, Ana (Coord.), «Cultura política y feminismos», Historia Social, 67 (II) 2010, pp. 60-171.

Aguado, Ana y SANFeliu, Luz, «Juventud, socialismo y compromiso político femenino: entre el asociacionismo y la militancia (1906-1931)», Ayer, 100, 2015, pp. 47-72. 
Arce Pinedo, Rebeca, Dios, patria y hogar. La construcción social de la mujer española por el catolicismo y las derechas en el primer tercio del siglo XX, Santander, Universidad de Cantabria, 2008.

Aresti Esteban, Nerea, Médicos, donjuanes y mujeres modernas. Los ideales de feminidad y masculinidad en el primer tercio del siglo $\mathrm{XX}$, Bilbao, Universidad del País Vasco, 2001.

ARESti EstebAN, Nerea, «Masculinidad y nación en la España de los años 19201930», Mélanges de la Casa de Velázquez, 42, 2, 2012, pp. 55-72.

BARbA PRIETo, Donato, «La Confederación Nacional de Estudiantes Católicos: orígenes, primeros pasos y consolidación (1920-1923)», Espacio, Tiempo y Forma, Historia Contemporánea, 12, 1999, pp. 117-131.

BE-Ami, Shlomo, «La rebellion universitaire en Espagne, 1927-1931», Revue d'Histoire Moderne et Contemporaine, julio-septiembre de 1979, pp. 365-390.

CAPEl MARTínez, Rosa, El trabajo y la educación de la mujer en España (19001930), Madrid, Ministerio de Cultura, 1982.

CARREÑo, Luciana, «La Federación Universitaria Hispanoamericana en Madrid», CIAN, Revista de Historia de las Universidades, 16/1, 2013, pp. 51-80.

Coвo Romero, Francisco, «Moldes teóricos y paradigmas historiográficos para el estudio de los "nuevos movimientos sociales"», en ORTEGA LóPEZ, Teresa María (ed.), Por una Historia Global. El debate historiográfico en los últimos tiempos, Granada, Universidad de Granada y Prensas Universitarias de Zaragoza, 2007, pp. 75-109.

CRESPO, Lola, «Introducción: La Juventud Universitaria Femenina (1920-1936)», en Maillard, María Luisa, Asociación Española de Mujeres Universitarias, 1920-1990, Madrid, A.E.M.U.-Instituto de la Mujer, 1990.

Del Moral Vargas, Marta, Acción colectiva femenina en Madrid, 1909-1931, Santiago de Compostela, Universidad de Santiago de Compostela, 2012.

DíAz FERnÁndez, Paloma, «La dictadura de Primo de Rivera. Una oportunidad para la mujer», Espacio, tiempo y forma. Serie V, Historia Contemporánea, 17, 2005, pp. 175-190.

DíAZ FreIRE, José Javier, «Cuerpos en conflicto. La construcción de la identidad y la diferencia en el País Vasco a finales del siglo XIX», en NASH, Mary y MARRE Diana (Eds.), El Desafío de la diferencia: Representaciones culturales e identidades de género, raza y clase, Bilbao, Universidad del País Vasco, 2003, p. 64-65.

ElEy, Geoff, Un mundo que ganar. Historia de la izquierda de Europa (18502000), Barcelona, Crítica, 2003.

ESPINOSA, María, «Influencia del feminismo en la legislación contemporánea», en Martín Gamero, Amalia, Antología del feminismo. Introducción y comentarios, Madrid, Alianza, 1975, pp. 193-200.

FAgOAgA, Concha, La voz y el voto de las mujeres. El sufragismo en España 1877-1931, Barcelona, Icaria, 1985. 
FleCHA, Consuelo, Las primeras universitarias en España, 1872-1912, Madrid, Narcea, 1996.

GonZÁlez CALleja, Eduardo, «Rebelión en las aulas: un siglo de movilizaciones estudiantiles en España», Ayer, 59, 2005, pp. 21-49.

González Calleja, Eduardo y Souto Kustrín, Sandra, «Juventud y política en España: orientación bibliográfica», Ayer, 59, 2005, pp. 283-298.

Margallón Portóles, Carmen, Pioneras españolas en las Ciencias. Las mujeres en el Instituto Nacional de Física y Química, Madrid, Consejo Superior de Investigaciones Científicas, 2014.

LoPÉZ-REY, José, Los estudiantes frente a la dictadura, Madrid, Javier Morata, 1930.

LUENGO LóPEZ, Jordi, Gozos y ocios de la mujer moderna: transgresiones estéticas en la vida urbana del primer tercio del siglo XX, Málaga, Universidad de Málaga, 2008.

MANGINI, Shirley, Las modernas de Madrid. Las grandes intelectuales españolas de la vanguardia, Madrid, Península, 2001.

Montero, Mercedes, «El acceso de las mujeres españolas en la universidad y su proyección en la vida pública (1910-1936)», AHIg, 18, 2009, pp. 311-324.

MonTERO, Mercedes, «Los primeros pasos hacia la igualdad: Mujer y Universidad en España (1910-1936)», Historia Crítica, 40, abril 2010, pp. 148-166.

Moreno, Mónica y ORTuÑo, Bárbara (eds.), «Género, Juventud y compromiso», Ayer, 100, 2015, pp. 13-147.

NASH, Mary, «Maternidad, maternología y reforma eugénica en España 19001939», en Duby Georges y PERRot Michelle (Dir.), Historia de las mujeres. El siglo XX, Taurus, Madrid, 1993, pp. 627-645.

NASH, Mary, Mujeres en el mundo. Historia, retos y Movimientos, Alianzaensayo, Madrid, 2004.

NASH, Mary, «De cultura política, cultura de género y aprendizaje del feminismo histórico en el Estado español», Desacuerdos, 7, 2012, pp. 18-41.

Pizzorno, Alessandro, «Algún otro tipo de alteridad: una crítica a las teorías de la elección racional», Sistema, 88, 1989, pp. 27-42.

Poveda Sanza, María, Mujeres y Segunda Enseñanza en Madrid (1931-1939), Tesis Doctoral inédita, Universidad Complutense de Madrid, 2013.

Ramos Palomo, M. ${ }^{a}$ Dolores, «El informe del Congreso Internacional de Estudiantes de Praga o la huella de la Institución Libre de Enseñanza en Victoria Kent (1921)», Arenal, 5/2, 1998, pp. 413-431.

SANFELIU, Luz, «Del laicismo al sufragismo. Marcos conceptuales y estrategias de actuación del feminismo republicano entre los siglos XIX y XX», Pasado y Memoria, 7, 2008, pp. 59-78.

Rose, Sonya O., ¿Qué es historia de Género?, Madrid, Alianza Editorial, 2012.

SASIAIN, Pamyra, «Federación Internacional de Mujeres Universitarias», en GALEANA, Patricia (coord.), Informe de las Instituciones gubernamentales dedicadas a la Mujer,México, D.F.,Universidad Nacional Autónoma de México, Federación Mexicana de Universitarias, 1996. 
Educación superior femenina y nuevas conformaciones identitarias...

ScotT, Joan W., Género e historia, México D.F., Fondo de Cultura Económica, Universidad Autónoma de la ciudad de México, 2008.

ScotT, Joan W., «El eco de la fantasía: la historia y la construcción de la identidad», Ayer, 62, 2006, pp. 111-138.

Souto KRUSTín, Sandra, «Juventud, teoría e historia: la formación de un sujeto social y de un objeto de análisis», Historia Actual Online, 13, invierno 2007, pp. 171-192.

TARROW, Sydney, El poder en movimiento. Los movimientos sociales, la acción colectiva y la política, Madrid, Alianzaensayo, 2004.

VALCÁCER, Amelia, La política de las mujeres, Madrid, Cátedra, 1997.

VÁZQUES RAMIL, Raquel, Mujeres y educación en la España contemporánea. La Institución Libre de Enseñanza y la Residencia de Señoritas de Madrid, Madrid, Akal, 2012.

White, Hayden, «Afterword», en BonNell, Victoria E. y HunT, Lynn (coords), Beyond the cultural turn. New directions in the study of society and culture, Berkeley, University of California Press, 1999, pp. 319-324.

XIRAu, Joaquín, Manuel B. Cossío y la educación en España, Barcelona, Ariel, 2. ${ }^{\mathrm{a}}$ ed., 1969.

\section{Financiación}

Este trabajo participa del Proyecto de Investigación HAR2014-57392-P Transiciones, movimientos sociales y democracia en el siglo XX. España en perspectiva comparada, y del Grupo de Excelencia Grupd'Estudis Històrics sobre les Transicions i les Democràcies (GEHTID) (PROMETEO/2016/108).

\section{Datos de la autora}

Luz Sanfeliu Gimeno (M.Luz.Sanfeliu@uv.es) es profesora titular del Departament d'Educació Comparada i Història de I'Educació de la Facultat de Filosofia i Ciències de l'Educació de la Universitat de València e integrante de l'Institut Universitari d'Estudis de la Dona. Sus líneas de investigación hacen referencia a las relaciones entre cultura política republicana y relaciones de género, en el ámbito de la educación informal i no formal, trabajando en campos como el asociacionismo y la sociabilidad femenina durante la II República. También, estudia los discursos y prácticas desarrolladas por las maestras laicas y las mujeres republicanas y socialistas vinculadas al feminismo a finales del siglo XIX y comienzos del XX. Ha publicado diferentes artículos y capítulos de libros y ha asistido a congresos nacionales e internacionales. Entre estos trabajos destacan el libro: Republicanas. Identidades de género en el blasquismo 1895-1910. 